\title{
Caracterização dos aspectos geomorfológicos do município de Irauçuba-ce como subsídio ao planejamento ambiental
}

\author{
Characterization of geomorphological aspects of Irauçuba -ce municipality as support to \\ environmental planning.
}

SILLVA ${ }^{1}$, F. L. F.

liewfelix@gmail.com

\begin{abstract}
Resumo
Este trabalho apresenta a caracterização geomorfológica do município de Irauçuba-ce, com objetivo de subsidiar ações voltadas ao planejamento e gestão ambiental necessário à sustentabilidade dos recursos naturais. Tendo em vista que os conhecimentos geomorfológicos fornecem subsídios para compreender a relação entre as formas de relevo e o processo de ocupação do espaço. A metodologia utilizada foi baseada em levantamentos bibliográficos, uso de imagens de altimetria Shuttlle Radar Topografhy Mission (SRTM) e trabalho de campo. Tratando-se das características geomorfológicas existentes no estado do Ceará, o município de Irauçuba apresenta cerca de $1.165 \mathrm{~km}^{2}$ sob o domínio da depressão sertaneja, $238 \mathrm{~km}^{2}$ representados pelos maciços residuais e cerca de $16 \mathrm{~km}^{2}$ de planícies aluviais, com formas específicas para cada compartimento.
\end{abstract}

Palavras-chave: Geomorfologia. Gestão Ambiental. Irauçuba.

\begin{abstract}
This work presents the geomorphological characterization of the municipality of Irauçuba-ce, in order to support actions aimed at environmental planning and management necessary for the sustainability of natural resources. Given that the geomorphological knowledge enables to understand the relationship between landforms and spatial occupation process. The methodology used was based on literature surveys, using altimetry images Shuttlle Radar Topografhy Mission ( SRTM ) and fieldwork. In the case of existing geomorphological features in the state of Ceará, the municipality of Irauçuba has about $1.165 \mathrm{~km}^{2}$ under the rule of country depression, $238 \mathrm{~km}^{2}$ represented by residual mass and about 16 square kilometers of floodplains, with specific shapes for each compartment.
\end{abstract}

Keywords: Geomorphology. Environmental management. Irauçuba.

\section{INTRODUÇÃO}

A geomorfologia é uma área da ciência geográfica que tem como objetivo estudar as formas de relevo, com o objetivo de entender os processos endógenos e exógenos nas fisionomias da superfície terrestre (CASSETI, 1995). A diversidade das formas de relevo dispostas sobre a superfície da terra facilita ou dificulta as múltiplas formas de uso, tornando imprescindível o planejamento para a apropriação de determinados espaços para a apropriação. Dessa forma os conhecimentos geomorfológicos são de fundamental importância para o planejamento ambiental, pois fornecem subsídios para compreender a relação entre as formas de relevo e o processo de ocupação do espaço, fazendo assim seu uso adequado de acordo com suas potencialidades e limitações morfológicas.

Nesse sentido, o presente trabalho tem como objeto de estudo o município de Irauçuba, localizado na porção norte do estado do Ceará. O relevo da maior parte do município é constituído 
por rochas do embasamento cristalino de idade pré-cambriana representadas por granitos, gnaisses e migmatitos diversos. Sobre esse substrato repousam coberturas aluviares, de idade quaternária, encontradas ao longo dos principais cursos d'água que drenam o município (RADAMBRASIL, 1981). A área de estudo possui clima tropical quente de seca acentuada - 7 à 8 meses (junho à dezembro), com pluviosidade média anual de $541 \mathrm{~mm}$ (janeiro à maio), e temperaturas médias mínimas que giram em torno de $27^{\circ} \mathrm{C}$ e máximas de $38^{\circ} \mathrm{C}$. As águas superficiais do município caracteriza-se pelo seu regime intermitente, no qual reflete a escassez e a alta variabilidade sazonal e interanual na região, com o padrão de drenagem variando de dendrítico a subdendrítico. Irauçuba faz parte de duas bacias hidrográficas, são elas: Bacia do Rio Aracatiaçu, que tem como um de seus afluentes o Rio Missi e Bacia do Rio Curu, que tem como principal afluente o Rio Caxitoré (FUCEME/IPECE, 2014).

De acordo com Jacomine (1973), foram identificados oito Associações de Solos, dentre as quais se destacam: Argissolo Vermelho-Amarelo Eutrófico, encontrado sob caatinga hipoxerófila e hiperxerófila, nas regiões de relevo ondulado a forte ondulado, Luvissolo, sob caatinga hiper e hipoxerófila em área de relevo plano a montanhoso, Planossolo, recoberto pela caatinga hiperxerófila, que ocorre, predominantemente, em áreas de relevo plano e, entre esses solos, ocorrendo inclusões de Neossolos.

Em termos gerais, o município de Irauçuba pode ser dividido em Depressão Sertaneja, Maciços Residuais e Planície Aluvial, com formas específicas para cada compartimento (PAM/ IRAUÇUBA, 2009).

Dessa forma, o presente trabalho tem como objetivo realizar a caracterização dos aspectos geomorfológicos do município de Irauçuba tendo em vista a identificação de áreas mais propícias para a ocupação e que, dessa forma, se possa contribuir com posteriores estratégias de planejamento territorial e ambiental.

\section{METODOLOGIA}

Os procedimentos para a realização do presente trabalho foram divididos em três etapas, sendo elas: Levantamento bibliográfico, Levantamento Cartográfico e Trabalho de Campo.

O levantamento bibliográfico consistiu na obtenção de informações relacionadas à temática da pesquisa, que subsidiou um arcabouço teórico referente aos conceitos de Geomorfologia e Planejamento Ambiental. Para isso, foram feitas consultas a livros, periódicos e artigos científicos, teses de doutorado e dissertações de mestrado disponíveis no acervo das bibliotecas da 
Universidade Estadual do Ceará (UECE), Universidade Federal do Ceará (UFC) e consulta a Internet de diversos trabalhos científicos que auxiliaram a pesquisa.

O Levantamento Cartográfico consistiu, inicialmente, na criação de um Banco de Dados Geográfico no software QGIS 2.8.8, utilizando como Datum de referência o sistema SIRGAS 2000 e coordenadas de referência UTM Fuso 24 Sul. Após a criação do Banco de Dados, foi feito a aquisição de imagem Shuttle Radar Topography Mission (SRTM), correspondente às cartas O3S405 e O4S405 do Estado do Ceará, mais precisamente do município de Irauçuba e municípios circunvizinhos, através do banco de dados geomorfométricos do Brasil - TOPODATA/INPE que através do método de krigagem disponibiliza dados refinados de sua resolução espacial original de $90 \mathrm{~m}$ para $30 \mathrm{~m}$.

O mapa de declividade foi gerado através dos algorítimos do GDAL (GDAL Analysis Slope), encontrados no software QGIS. Os intervalos selecionados para a declividade seguem a proposta de EMBRAPA (1979), sendo: a) valores inferiores a 3\% - relevo plano; b) entre 3 a $8 \%$ relevo suave ondulado; c) 8 a 20\% - relevo ondulado; d) 20 a 45\% - relevo forte ondulado; e) 45 a $75 \%$ - relevo montanhoso; f) superior a 75\% - relevo forte-montanhoso. Para a classificação da declividade, foram utilizados os algorítimos do GRASS (Raster - r.reclass), no qual foi expressa em porcentagem.

Através da imagem Shuttle Radar Topography Mission (SRTM), citada acima, foi criado o mapa hipsométrico. Com a camada Raster adicionada, foi configurado seu estilo de renderização, ou seja, foi dado cores da legenda hipsométrica para cada camada de elevação. Essas cores foram elaborados a partir da adaptação dos valores de elevação e regras de cores contidos nos esquemas de cores SRTM, Terrain, Atlas Shader e ETOPO2 provenientes do software GRASS (função r.colors), encontrados no software QGIS. As curvas de nível foram criadas no interval de $100 \mathrm{~m}$, variando de $0 \mathrm{~m}$ a $900 \mathrm{~m}$ de altitude.

\section{RESULTADOS E DISCUSSÃO}

As características geológicas e geomorfológicas são de fundamental importância, pois possibilitam conhecer a área de estudo levando em consideração a sua gênese, estrutura e processos de formação, determinando assim as formas de relevo e sua dinâmica na superfície terrestre. À vista disso, a área de Irauçuba integra a região de Dobramentos Nordeste ou Província Borborema, mais especificamente Maciço Mediano de Santa Quitéria (SOUZA FILHO, 1998). Estudos geológicos e hidrogeológicos realizados por Souza Filho (1998), identificou três grandes unidades précambrianas de idades distintas: terrenos Ortognáissico e Mígmatíticos, originados provavelmente no 
ciclo transamazônico, os terrenos Supracrustrais originados no Meso-Neoproterozóico e os terrenos Granitóides resultantes do evento Tectono-Termal Brasiliano, no Neoproterozóico.

Sob o ponto de vista hidrogeológico, as potencialidades hídricas da área de estudo ocorrem em função das peculiaridades físicas que inserem o município no semiárido. O município possui baixo potencial de águas subterrâneas, tanto em termos quantitativos como qualitativos. Isso se dá por conta da natureza do substrato geológico, onde predominam rochas cristalinas recobertas por um manto intemperizado pouco desenvolvido, associado às condições climática de semiaridez, se reflete em uma importante deficiência hídrica nessa região.

Conforme Bastos e Cordeiro (2012), o Nordeste brasileiro apresenta uma grande variedade de feições geomorfológicas que se justificam principalmente por fatores estruturais e climáticos. Nesse contexto pode-se destacar as depressões sertanejas como unidade geomorfológica, porém existem inúmeras feições residuais, como campo de Inselbergs e maciços cristalinos. Dessa forma, tratandose das características geomorfológicas existentes no estado do Ceará, o município de Irauçuba apresenta cerca de $1.165 \mathrm{~km}^{2}$ sob o domínio da depressão sertaneja, $238 \mathrm{~km}^{2}$ representados pelos maciços residuais e cerca de $16 \mathrm{~km}^{2}$ de planícies aluviais (PAM/ IRAUÇUBA, 2009).

A Depressão Sertaneja caracteriza-se por apresentar amplas superfícies de erosão embutidas entre os planaltos cristalinos e sedimentares, em cotas altimétricas inferiores a 350 metros, elaboradas por processos de pediplanação que truncam indistintamente várias litologias. Em Irauçuba a depressão sertaneja corresponde cerca de 65\% da área do município, com topografias planas e quase planas (3\% de declividade), exibindo-se morfologicamente como rampas inclinadas para a direção dos fundos de vales e litoral. Na sua morfogênese, em virtude das condições climáticas, predominam os processos físicos de alteração das rochas. Deve-se, no entanto, considerar a atuação da erosão diferencial que devido à heterogeneidade litológica, isola os relevos residuais que se apresentam em formas de planaltos e cristas, constituindo Maciços Residuais (SOUZA, 1979 e 1986; RADAMBRASIL, 1981). Conforme Brandão (2003), os solos nesse ambiente são representados pelos Luvissolos pouco profundos, bem drenados, textura argilosa, cascalhento e de alta fertilidade natural, os quais se alternam com os Nelossolos litólicos que se apresentam rasos, textura arenosa, pedregosos e de média fertilidade natural. A cobertura vegetal representada nessa unidade geomorfológica é representada pelas Caatingas Arbustivas Densas e as Caatingas Arbustivas Abertas, ambas bastantes alteradas, por conta da retirada de lenhas, para fins produtivos de ferragens no estrato herbáceo no sistema de uso de terra para pecuária extensiva. 
Em meio a Depressão Sertaneja encontra-se a Planície Aluvial ou áreas de acumulação inundáveis, no qual correspondem a setores mais rebaixados, em cotas altitudinais inferiores a 200 metros, constituindo-se em uma unidade morfopedológica individualizada pela ocorrência de relevo plano ou suavemente ondulado, sujeito a inundações periódicas (SOUZA, 1988). A planície é uma forma de relevo topograficamente mais rebaixada e também denominada leito maior da calha do curso fluvial (CHRISTOFOLETTI, 1981). Essa unidade geomorfológica é constituída por depósitos quaternários de sedimentação fluvial que dão origem aos Neossolos Flúvicos, aos Planossolos Solódicos, aos Solos Halomórficos e aos Neossolos Litólicos. A vegetação que repousa nessa unidade geomorfológica é representada pela ocorrência de um tapete herbáceo-graminóide, que se apresenta continuo na estação chuvosa, formando extensas áreas de campos, no período de estiagem a vegetação é submetida ao pastoreio e a paisagem é representada pela exposição completa dos solos.

Finalizando a compartimentação têm-se os Maciços Residuais, no entendimento de Souza (1988), os maciços residuais apresentam formas dissecadas, elaboradas por erosão diferencial em rochas cristalinas e cristafolianas, principalmente rochas metamórficas representando as serras e serrotes que se destacam pelas elevadas altitudes (400-600 metros e 700-800 metros) dispersos na Depressão sertaneja. Suas feições morfológicas são representadas por cristas de topos aguçados, colinas de topos convexos e vales em forma de V. As cristas são formas aguçadas com vertentes retilíneas e alongadas, com classe de declividade pronunciada, o que condiciona o aparecimento de escarpas e vertentes rochosas expostas. As colinas são configuradas por apresentarem vertentes mais curtas e topos de formas convexas mais suaves em comparação às cristas.

Em Irauçuba, os relevos residuais tanto ocorrem agrupados, como isolados na forma de inselbergs, quase sempre com declividades superiores a 30\% (CPRM, 2003). No setor nortenordeste do município, destaca-se o maciço residual de Uruburetama, que se encontra profundamente dissecado em um conjunto de cristas, patamares e profundos vales encaixados em "V" sob forte controle estrutural (SOUZA; OLIVEIRA, 2006). Este maciço residual é constituído por granitos e granodioritos de idade neoproterozoica (CPRM, 2003). Outro conjunto de relevos residuais de destaque na área localizando-se no setor sul-suldeste do município, representado pelas serras de Santa Lúcia do Frigel e Santa Luzia da Catarina. Os solos da unidade geomorfológica são representados pelos Podzólicos vermelho-amarelo de fertilidade natural média e solos Litólicos (rasos) e afloramentos rochosos, alternando-se com a cobertura vegetal, que encontra-se intensamente alterada, principalmente no setor norte do município (Maciço Residual de Uruburetama), os últimos remanescentes indicam que no passado havia a predominância de 
Florestas Caducifólias e Subcaducifólias regionalmente denominadas de matas secas, e de áreas de transição dessas florestas para a caatinga.

Porém as atividades desenvolvidas, por vezes, não são compatíveis com a capacidade de suporte de cada unidade geomorfológica mencionada, ocasionando impactos ambientais. As atividades exercidas no município estão diretamente ligadas a pecuária intensiva e as práticas da agricultura de subsistência, as quais são exercidas por meio de técnicas de manejo rudimentares que ocasionam a degradação ambiental, perda da fertilidade natural dos solos, desencadeamento de ações erosivas em áreas degradadas e empobrecimento da biodiversidade. Os solos que compõem parte significante do município, tem elevado grau de impermeabilidade favorecendo a permanência de águas superficiais e um tapete herbáceo-graminóide, formando grandes áreas de campos durante as chuvas e a exposição completa dos solos no período de estiagem, quando a vegetação é submetida ao pastoreio. Nesta situação, é necessária uma avaliação cuidadosa da relação das atividades que são desenvolvidas na área de estudo e o impacto dessas na degradação ambiental local.

Futuros planejamentos ambientais requerem sobretudo o conhecimento das feições geomorfológicas existentes no ambiente que se esteja trabalhando, pois, de acordo com Suertegaray (2002), o relevo, sendo um constituinte da paisagem geográfica, deve ser entendido como um recurso natural imprescindível para uma gestão ambiental adequada. Nesse sentido, Bastos e Cordeiro (2012), permitem identificar e avaliar as formas de relevo e sua dinâmica em relação aos solos e cobertura vegetal, relacionando-os com os demais componentes geoambientais. Logo, a abordagem holística dos aspectos naturais é imprescindível para entender o funcionamento do relevo no momento atual e as possíveis implicações que podem ocorrer de um mau uso e ocupação da terra. 


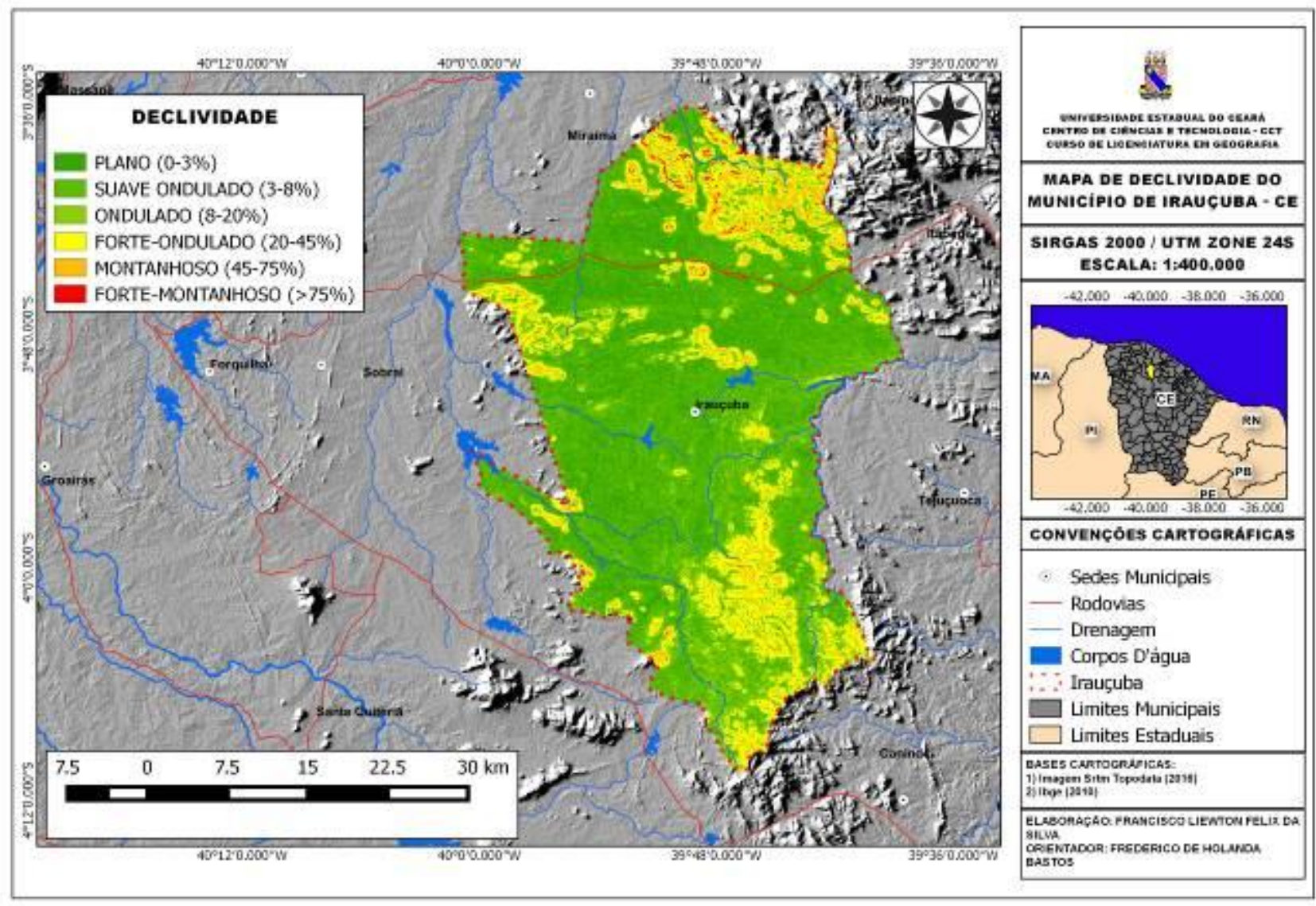

Figura 01. Mapa de Declividade do município de Irauçuba-ce. Fonte: Silva e Bastos (2016)

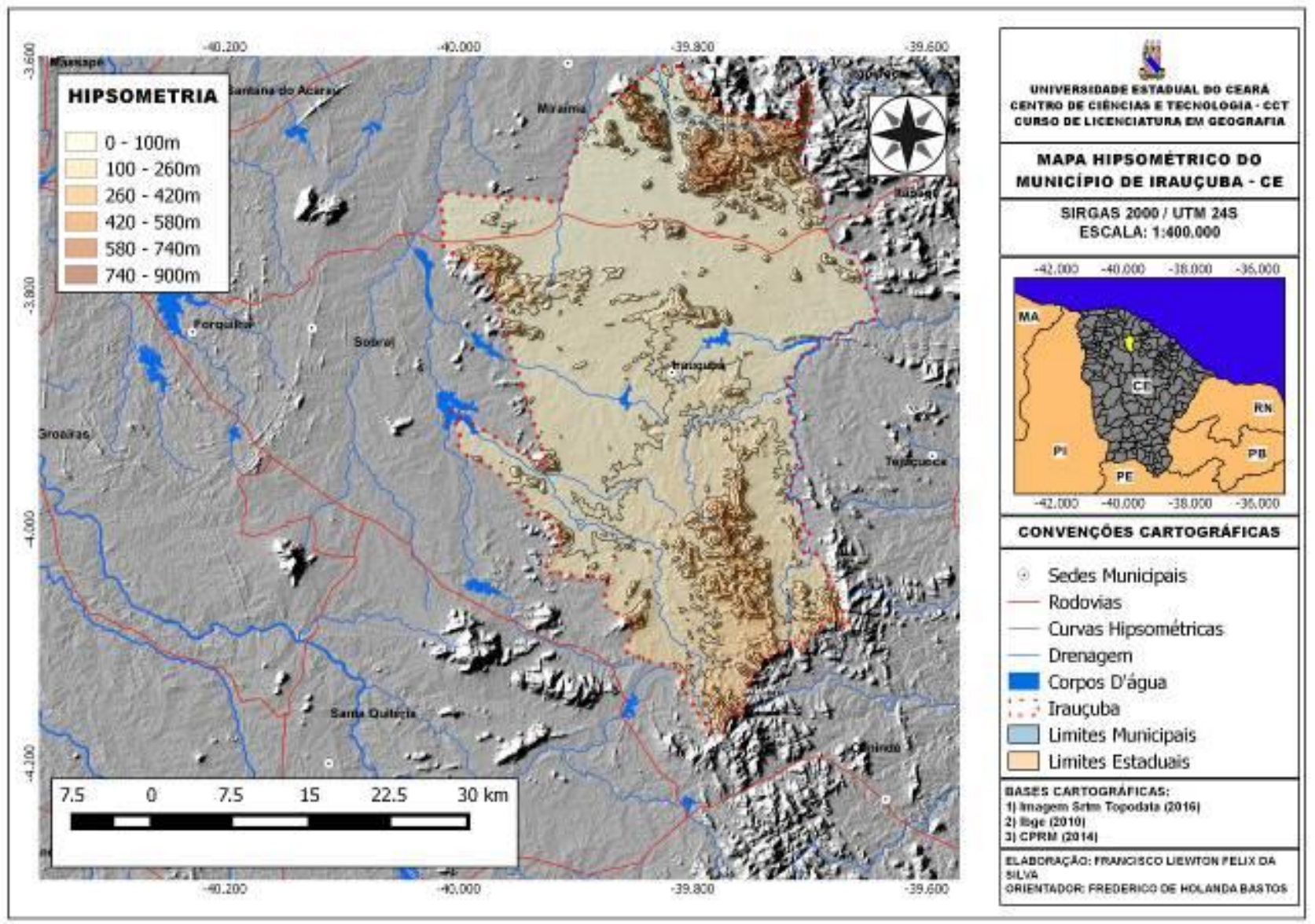

Figura 02. Mapa Hipsométrico do município de Irauçuba-ce. Fonte: Silva e Bastos (2016) 


\section{CONSIDERAÇÕES FINAIS}

Ter um uso adequado dos recursos naturais é, sobretudo, instigar uma manutenção da capacidade produtiva desses recursos. O planejamento ambiental é uma das ferramentas mais precisas no que condiz ao ordenamento territorial. O estudo dos recursos naturais tem como principal foco estabelecer diretrizes frente às tipologias de uso exercidas sobre os ambientes, de acordo com as potencialidade e limitações de cada ambiente. No entendimento de Rodriguez e Silva (2010), o planejamento ambiental tem uma ligação intrínseca com os elementos ambientais, sendo estes variáveis indispensáveis em uma análise ambiental. Para Ross (2009), o planejamento é um processo contínuo que envolve a coleta, organização e análise sistematizadas das informações, por meio de procedimentos e métodos, para chegar a decisões ou a escolhas acerca das melhores alternativas para o aproveitamento dos recursos disponíveis.

A análise do relevo do município de Irauçuba possibilita o entendimento da dinâmica natural do ambiente e pode apontar os limites e as potencialidades do local. As áreas topograficamente planas apresentam condições ambientais favoráveis à prática de atividades agrícolas, desde que utilizadas técnicas de manejo adequadas. Por outro lado, o relevo dissecado limita o uso do ambiente, pois não é próprio para grandes ocupações humanas e não é possível o cultivo de culturas agrícolas. As planícies fluviais é uma área propícia à prática de lavouras irrigadas em função das boas condições de solos e disponibilidades hídricas.

Quanto ao forte quadro de degradação que ocorre no município, é necessário que se adote práticas educativas, que promovam a recomposição florística da caatinga utilizando técnicas de conservação dos solos para atenuar os efeitos da morfodinâmica sertaneja, além de medidas que estabeleçam setores ambientais estratégicos para fins conservacionistas, levando em conta a capacidade de suporte que cada unidade geomorfológica.

\section{REFERÊNCIAS}

BASTOS, F. H.; CORDEIRO, A. M. N. Fatores naturais na evolução das paisagens no semiárido brasileiro: uma abordagem geral. REVISTA GEONORTE, Edição Especial, v.2, n.4, p.464 - 476, 2012.

BRASIL. COMPANHIA DE PESQUISA DE RECURSOS MINERAIS. Atlas digital de geologia e recursos minerais do Ceará. Mapa na escala de 1:500.000. Fortaleza: Serviço Geológico do Brasil/Ministério das Minas e Energia, 2003. 
BRANDÃO, R de L. Zoneamento Geoambiental da região de Irauçuba - CE. Texto explicativo, Carta geoambiental. Fortaleza; CPRM, 2003.

CASSETI, V. Ambiente e apropriação do relevo. 1. ed. São Paulo: Contexto, 1995.

CHRISTOFOLETTI, A. Geomorfologia fluvial: o canal fluvial. 2 ed. São Paulo: Edgard Blücher, 1981.

EMPRESA BRASILEIRA DE PESQUISA AGROPECUÁRIA - EMBRAPA. Serviço Nacional de Levantamento e Conservação de Solos (Rio de Janeiro, RJ). Súmula da 10. Reunião Técnica de Levantamento de Solos. Rio de Janeiro:1979. 83p. (Embrapa-SNLCS. Micelânea, 1).

INSTITUTO BRASILEIRO DE GEOGRAFIA E ESTATÍSTICA - IBGE. Censo Demográfico de 2014. Fortaleza-CE, 2014. Disponível em: http://www.censo2010.ibge.gov.br/dados_divulgados/index.php?uf=23. Acessado em: 29 de janeiro de 2015.

INSTITUTO CACTOS. Plano de Ação Municipal de Combate a Desertificação de Irauçuba. Irauçuba/ CE, 2009.

INSTITUTO DE PESQUISA E ESTRATÉGIA ECONÔMICA DO CEARÁ- IPECE. Perfil Básico Municipal - Irauçuba. Secretaria do Planejamento e Coordenação. Fortaleza- CE. 2014.

JACOMINE, P. K. T. et al. Levantamento exploratório - reconhecimento de solos do estado do Ceará. Recife: SUDENE/DRN, v. 2, 1973. (Boletim de Pesquisa n. 28).

PROJETO RADAMBRASIL. Levantamento de Recursos Naturais Volume 21: Folha SA.24 Fortalezas; geologia, geomorfologia, solos, vegetação e uso potencial da terra. Ministério das Minas e Energia - MME/DNPM, Rio de Janeiro, 1981.

RODRIGUEZ, J.M. e SILVA. E. V. da. Geoecologia: Uma visão das Paisagens. Fortaleza: Edições UFC, 2010. $222 \mathrm{p}$

ROSS, J. L. S. Geomorfologia, Ambiente e Planejamento. Coleção Repensando a Geografia. São Paulo: Editora Contexto, 1990, 84p.

SOUZA FILHO, O. A. de - 1998 - Geologia e Mapa de Previsão de Ocorrência de Água Subterrânea Folha SA. 24-Y-D-V - Irauçuba, Ceará. Dissertação de Mestrado. Universidade Federal de Ouro Preto-MG.

SOUZA, M. J. N. Compartimentação Topográfica do Estado do Ceará. Revista Ciência Agronômica, Fortaleza, v. 9, 1979.

- Contribuição ao Estudo das Unidades Morfo-Estruturais do Ceará. Revista de Geologia (Fortaleza), Fortaleza, v. 1, 1988.

Funece, 2000, 28-31p.

; Compartimentação Territorial e Gestão Regional do Ceará. Fortaleza: Editora

.; OLIVEIRA. V. P. Os enclaves úmidos e subúmidos do semiárido do nordeste brasileiro. Revista de geografia /UFC, n. 09, 2006. p. 85-102.

SUERTEGARAY, D. M. A. Geografia Física e Geomorfologia - Uma (Re)Leitura. Porto Alegre: Ujuí, 2002.

Recebido em: 14/08/2016

Aceito para publicação em: 01/10/2016 